\title{
Measuring crime through victimization: some methodological lessons from the ICVS
}

\begin{tabular}{|r|l|}
\hline Journal: & European Journal of Criminology \\
\hline Manuscript ID & EUC-17-0148.R1 \\
\hline Manuscript Type: & Article \\
\hline Keywords: & $\begin{array}{l}\text { Comparative criminology, Crime statistics, ICVS, Statistical bias, } \\
\text { Victimization surveys }\end{array}$ \\
\hline Abstract: & $\begin{array}{l}\text { The objective of this study is to demonstrate that there are design errors in } \\
\text { the International Crime Victims Survey (ICVS) that lead to biases in the } \\
\text { estimates of victimization rates. This will be verified, firstly, by comparing } \\
\text { the crime rate derived from the ICVS microdata with the based on the } \\
\text { reference population and, secondly, examining the consequences of two } \\
\text { ICVS methodological decisions: the use of individual weights and the re- } \\
\text { weighting procedure in accordance with the household size. These sample } \\
\text { design failures that generate distorted crime rankings, calls for the need to } \\
\text { make corrections in both the subsequent waves of the ICVS and in the final } \\
\text { design of a future European survey. }\end{array}$ \\
\hline
\end{tabular}

SCHOLARONE ${ }^{m}$

Manuscripts 


\title{
Measuring crime through victimization: some methodological lessons from the ICVS
}

\author{
Introduction \\ "It is hard to think of another policy area where the concern is so high, the \\ expenditures are so high, and the knowledge base is so thin". These words, referring to \\ the policies aimed at addressing crime and criminal justice concluded an excellent \\ study conducted by Blumstein and Petersilia a few years ago. ${ }^{1}$ Although the comments \\ were made in relation to the United States, this situation also affects the countries of \\ the European Union (EU).
}

In the field of criminal policy, information in itself does not guarantee rational decision-making, as stated by Delmas-Marty (1990: 963), but quality information at least makes it more difficult to adopt irrational decisions. It is very important to bear this in mind when considering the risk of populist criminal policies (which seek to please the people) and politicized policies (directed towards electoral objectives), such as those implemented over the last few decades in some countries, irrespective of the information on the crime situation —Aebi et al. (2002: 22)—, and the dominant trend 
towards the expansion of criminal law as maintained by Silva (2011: 4). In short, it is essential to proceed in a scientifically informed and rational way to fulfil the genuine political-criminal objectives that should be sought by the states.

However, in order to obtain useful information about crime, collecting data on the country in question is not enough. The data need to be compared with those of other countries in order to appreciate the true meaning of the results. This requires drawing more precise information from data sources that can be compared with one another. In practice, this is highly difficult as the different legal systems vary in aspects which are fundamental for making this comparison (different names for offences, different requirements for the prosecution to instigate criminal proceedings, etc.). The comparison of the data is also essential, of course, when designing policies on a regional scale, as the European Commission (2012: 2) has pointed out.

With these objectives, for over a century, both formal and informal comparative statistical studies have been carried out on the crime situation in different countries using various approaches and methodologies. ${ }^{2}$ Prima facie, the conviction records should be able to provide the most reliable data (Aebi and Linde, 2011), as only judges are able to definitively qualify a conduct as a crime. However, there are several drawbacks to using conviction statistics, such as incidents which are not always reported in certain crime areas, or due to the dark figure of crime, differences 
between countries with respect to the categories and names of offences or differences in the rules by which multiple offences are counted. ${ }^{3}$ A further difficulty lies in the fact that there may be a delay of several years between the recording of the judgement and the moment when the offence was committed. Therefore the information necessary for making important decisions in criminal policy, such as legislative reforms, may be available too late.

In view of these difficulties, the offences recorded by the police are often used. However, police statistics are also problematic because there is a lack of uniformity in the collection of data (differences in the time and way in which the police define, file and count offences), which can vary from country to country depending on how the victims behave when reporting (Bouten et al.,2003: 1-2 or Aebi, 2010). Also, if there is a temporary concentration of police efforts on certain crimes. ${ }^{4}$ In the case of the EU, the police statistics of recorded crimes collected are also affected by many factors and the EUROSTAT (2016a, b and c) indicates that direct comparisons of crime levels in different countries should be avoided.

As a result of these problems and the need of alternative sources, the testimonies of crime victims collected in victimization surveys are being used. These surveys constitute another statistical source with which the judicial and police data can be compared and complemented. Although they are not without problems, such as 
the economic cost of their undertaking (Mankkinen, 2008: 132), the small sample size (Van Dijk et al., 2007: 11), their irregularity over time or their frequently unofficial nature, they also have undeniable advantages, such as the access to crime figures that would otherwise be hidden and the possibility of obtaining homogeneous statistical information.

One of the most internationally recognized victimization surveys is the International Crime Victims Survey (ICVS). The ICVS was created to respond to the need for reliable crime statistics that could be used for international comparisons (Van Dijk et al. 2007: 11), due to the insufficiency of other instruments that measured the nature and size of crime (Bouten et al. 2003: 1). When using the ICVS, there is no need to assume - in theory — the problems inherent in police statistics because the results are harmonized and, therefore, methodologically comparable.

The EU has also proposed its own victimization survey. It was promoted by the European Commission based precisely on the ICVS and followed the mandate of The Hague (2004-2009) and the Stockholm (2010-2014) Programmes regarding Freedom, Security and Justice in the EU. The aim was the design of a victimization survey which would be comparable across the member countries and which would provide data on crime as a complement to police records. According to Van Dijk et al. (2010), the development of this task was placed in the hands of the EUROSTAT, which contacted 
many groups and institutions to discuss and propose what subsequently became known as the EU Safety Survey (EU-SASU).

In 2011, the European Commission submitted a proposal to the European Parliament (EP) to conduct the EU-SASU in 2013. As a preliminary step, the EU-SASU questionnaire was pretested using an adjusted and shortened version of the ICVS. However, as indicated by Heinz (2016), at the end of 2012, the EP rejected the proposal because of concerns over the survey's costs and questions regarding its "added value", given that some member states were already conducting their own victimization surveys. ${ }^{5}$

Given that the initial proposal of the European EU-SASU was based on the ICVS, this study seeks to review certain aspects of the ICVS that may affect the estimates of victimization, both of the possible European survey and the new waves of the international survey. In fact, although the ICVS is an unofficial survey as it does not form part of the National Statistics Plans and its continuity is subject to the availability of funding, it is widely accepted as one of the most important tools for the harmonized measurement and comparison of crime in different countries.

With this objective, the first section of the study summarises the main features of the ICVS from a statistical point of view. The second section analyses the possible 
causes for the biases in the estimates of victimization rates based on this survey. On the one hand, the existence of differences between the final sample and the reference population are assessed in terms of age and sex structure, the size of households and the labour force status, in order to determine whether they can lead to distortions in the estimated rates. On the other hand, the biases due to certain methodological decisions in the ICVS are highlighted. Specifically, these decisions are related to considering the victimization of the household - for some crimes instead of that of the individual — and, also to giving greater weight to the responses of those interviewees who reside in large households. The third section provides an estimate of the effects of these biases on the victimization rates of the ICVS-2004/05. The study closes with conclusions and recommendations and finally the bibliographic references are listed.

\section{The statistical design of the ICVS: basic features}

The ICVS is the most comprehensive instrument developed so far in order to monitor and study the volume of crime, the perception of crime and attitudes towards the criminal justice system from a comparative and international perspective. The standardization of the questionnaires used and other aspects of data collection assure that data can, within confidence margins, be reliably compared across countries (Van Dijk et al., 2007: 5). The survey was first carried out in 1989 and since then there have 
been five more waves; specifically, in 1992, 1996, 2000, 2004/2005 and the last one (uncompleted) ${ }^{6}$ between 2010 and 2015.

The ICVS-2004/05 was the last complete round of the survey which, on that occasion, was conducted in thirty countries. Its microdata files -anonymized individual data - are available at the official website of the $\mathrm{ICVS}^{7}$ and there is an extensive official report in Van Dijk et al. (2007). Specifically, the 2004/05 round of the ICVS was coordinated by the United Nations Interregional Criminal Justice Research Institute (UNICRI) and the United Nations Office on Drugs and Crime (UNODC). The operation was divided into two parts: the surveys conducted in the member states of the EU and the surveys conducted in countries outside of the EU. In order to execute the project in the EU countries, a consortium was created led by Gallup Europe and formed by UNICRI, the Max Planck Institute (Germany), the CEPS/INSTEAD (Luxembourg) and GeoX Ltd. (Hungary) which received funds from the European Commission's Directorate General for Research (Van Dijk et al., 2007: 23). In 2005, the consortium carried out the European part of the survey, giving it the name EU International Crime Survey (EU-ICS).

The types of offences covered by the ICVS-2004/05, the content is similar to that of almost all of the victimization surveys aimed at individuals residing in households. It covers "common crimes": theft (of personal properties, of —and 
from - cars, of motorcycles and bicycles), burglary (included attempted), robbery, assaults and threats, sexual offences (against women or men) and car vandalism. However, through a set of specific questions, the ICVS of 2004/05 also gathers information about non-conventional crimes such as street level corruption (bribeseeking by public officials), consumer fraud and "hate crimes" (Van Dijk et al., 2007: 27). The survey is exclusively limited to considering crimes committed against clearly identifiable individuals, excluding victims under the age of sixteen.

In all of the participating countries, the survey data are drawn from a random sample who are mostly interviewed by telephone using the CATI system (Computer Assisted Telephone Interview. The telephone numbers called are generated randomly through the random dialling of digits and are included in the survey following the geographical stratification (distribution) criterion, which in the case of the $\mathrm{EU}$, is that of the NUTS 2 (Van Dijk et al., 2007: 28).

Surveys which apply the CATI methodology usually have a low response rate. This is a concern for statisticians because it could generate biases when the characteristics of the people who do not respond (due to absence or refusal) are different to those of the sample finally interviewed. Although efforts were made to minimize this bias, the average response rate obtained in the fifteen European 
countries where the random dialling of digits was used only amounted to $46.3 \%$ of the calls (Van Dijk et al., 2007: 32-34).

As is usually the case in other surveys, the results of the ICVS-2004/05 are based on data that have been weighted in order to render the samples representative of the structure of the population aged sixteen and over in terms of gender, regional distribution, age and household composition. This weighting is carried out in accordance with what each interviewee represents in the target population (individual weight). Also, in order to compensate the over-representation or under-representation of specific groups of the population in the final samples of the ICVS, different reweighting adjustments were made. First, in order to balance the different households sizes, the individual weight of interviewed in large ones has been increased; second, to counter the fact that the size of the sample in the main cities was very large with respect to the total sample of the country. Therefore, the weight of this group was reduced. And finally, the weights were adjusted in order to obtain the same distribution by age, gender and region as the census data in each country (Van Dijk et al., 2007: 38-40). The ICVS-2004/05 report clarifies that in order to carry out these adjustments, the most recent external statistics on the population according to its composition by sex, age and regional distribution were used. However, due to the fact that in the majority of countries the statistics on the distribution of the population 
aged sixteen and over in households were not available or were not suitable, these corrections were derived from the survey itself $\left(\right.$ sic). ${ }^{8}$ The final weights of the individuals were generated through an iterative process whereby the marginal totals of the weighting factors by gender and region corresponded to the values in the population (Van Dijk et al., 2007: 191-192).

\section{The sources of bias in the ICVS}

The homogenization of all aspects of the survey across a large number of countries is unattainable (Van Dijk et al, 2007 and Pérez-Cepeda and Benito-Sánchez, 2013). The unequal circumstances in which the survey is conducted, ${ }^{9}$ in the degree of preparation of the interviewers or in the period in which the fieldwork is undertaken, may generate a first source of bias in the victimization rates. Furthermore, in a statistical operation such as the ICVS, there could be another cause of bias that arises from the so-called error response. The ICVS can only reflect the facts that the victims (and their sensitivity) are prepared to reveal to the interviewers. As indicated by Van Dijk et al. (2007: 37), certain groups (for example, people with a higher level of education) are more inclined to remember and express minor violent incidents; or, on the contrary, some people may not be aware of the relevance of an incident or simply because 
cultural sensitivity may affect the disposition of the interviewee with respect to some forms of violence, particularly sexual offences.

Neither the first type of bias (due to the lack of homogeneity) nor the second type (due to response error) can be easily controlled or estimated. However, they must be taken into account when making international comparisons of victimization levels. However, it is possible to verify both the presence and the potential effects of other sources of bias in the ICVS estimates. The victimization rates can also be distorted by the existence of substantial differences between the structure of the population estimated by the survey and the target population. Furthermore, equally important are the biases generated by two methodological decisions of the ICVS. The first consists in counting the number of victimizations of all members of the household for certain offences (basically theft of/from vehicles) in combination with the individual weighting factor — and not the household one-. The unsought consequence is that a higher number of offences per person will be estimated. The second derives from the fact that the individuals who belong to large households are given greater weight. The association of all these factors will necessarily tend to overvalue the national victimization rates.

In order to estimate these biases and illustrate the changes that could arise in the victimization ranking of countries, a group of seven EU countries has been selected 
which are included in the microdata files of the last complete round of the ICVS, carried out between 2004 and $2005 .{ }^{10}$ More specifically, due to their representativeness, three of the large EU powers have been selected (Germany, France and the United Kingdom) together with two medium-sized Mediterranean countries (Spain and Italy) and, finally another two smaller Atlantic countries (Ireland and Portugal). These seven countries accounted for $68.6 \%$ of the population of the seventeen EU countries included in the ICVS $2004 / 05$ and $62.3 \%$ of the area.

These seven samples taken in 2005 are used with the registers (people surveyed) weighted by the w005a variable (individual weight) which is the same individual weight that has been used in the official reports of the ICVS. ${ }^{11}$ Table 1 shows the number of people surveyed in each of the countries selected in 2005 . These figures, calculated from the microdata, coincide exactly with those provided in the official codebook of the survey carried out by Van Kesteren (2007: 11).

\section{(Table 1 about here)}

Before continuing, it should be clarified that the annual incidence rate of victimization (number of times that the population aged 16 and over has been victim to a crime throughout the year prior to the survey) has been used, rather than the annual prevalence rate of victimization (population aged 16 and over who have been the victims of at least one offence during the year prior to the survey). 
In fact, prevalence and incidence are two complementary concepts and the greater or lesser relevance given to each of them depends on the ultimate objective. Two areas with the same incidence rate can have different prevalence rates, depending on the higher or lower concentration of victimizations in certain population groups; and vice versa. In our opinion, the incidence rate is a better indicator of the intensity of the problem as it provides the frequency of the appearance of incidents, so it is more appropriate for making international comparisons for the ultimate purpose of improving the legal regulation. On the other hand, the prevalence rate indicates the presence or not of victimization and its extension, but not its intensity. If there is a low prevalence, victimization may be experienced by a small percentage of the population, but with high intensity; therefore, this concept may be more useful for designing social policies in favour of certain population groups or to improve the situation of specific geographic areas in which victimization is concentrated. In addition, the incidence rate would be the most appropriate measure in any exercise of triangulating victimization data with those of the police records in order to evaluate the dark figures of crime.

As the annual incidence rate is more suitable for measuring effective levels of victimization and it is sensitive to the effects of the biases in the ICVS estimates, we have chosen it for the study, although in the ICVS the preference is for the prevalence 
rate. Throughout the text, the incidence rate is also referred to as the victimization rate.

Differences between the final sample and the reference population

It is assumed that the weighting factor modulates the sample to render it the most representative of the national population aged 16 and over in terms of gender, age, geographical distribution and household size. Therefore, it can be considered that when the ICVS sample is weighted by the final individual weight variable, w005a, we are taking into account all of these details so that the victimization rates and other derived indicators are not biased.

A simple way of ensuring this is to confirm that the final distribution of the weighted sample is sufficiently similar to the distribution of the target population, in our case, the resident population of each of the seven countries included in Table 1. Insofar as the structure of the weighted sample differs from that of the real population, it is highly probable that the estimated indicators are biased. ${ }^{12}$ Therefore, and limited by the variables of the ICVS that can be compared with other external and official statistical sources, the structures have been examined by age and sex, the distribution of the households by size and the labour force status. For the seven countries selected, we have used official harmonized data centralized in the 
EUROSTAT. Specifically, the resident population at 31 December 2005 in each country by age and sex; the EU Statistics on Income and Living Conditions (EU-SILC) for the size of households and the EU Labour Force Survey (EU-LFS) for the labour force status.

Both the quality of the national population data and that of the two surveys EU-SILC and EU-LFS - is confirmed by the EUROSTAT, so there is no doubt that they are representative of the target population, and therefore appropriate for making the comparison. On the one hand, the population figures are those transmitted directly by the countries to the EUROSTAT and are drawn from their own resident population statistics. On the other hand, the EU-SILC is anchored in the European Statistical System and based on harmonized criteria for all EU countries. ${ }^{13}$ And the EU-LFS is the largest European household sample survey, providing quarterly and annual data on labour participation of people aged 15 and over. Due to the diversity of information and the large sample size, the EU-LFS is also an important source for other European statistics, e.g. education statistics or regional statistics (EUROSTAT, on-line b).

Differences in the structure in terms of age and sex. Figure 1 shows the age distributed in five-year intervals of the weighted sample of the ICVS-2004/05 and of the EUROSTAT population at 31 December 2005 in the seven selected countries. It can be clearly observed that there are significant imbalances in the participation of each age group. In this sense, although the underestimation of the population aged 70 and over 
in the survey is notable, what is most relevant is the frequency with which the ICVS sample underestimates the young adult $-25-39$ years-, while it systematically overestimates the more mature age segments, specifically the 50 to 70 year-old group.

As the probability of being a victim of a crime is not uniform and varies depending on the age segment, the aggregate victimization rates estimated by the ICVS will be biased. If we assume, for example, the existence of a higher victimization rate among the 25-39 year-old age segment and a lower degree of criminal incidence among individuals between the ages of 50 and 70, when the former group is overestimated and the second is underestimated, the aggregated victimization rate would have a downward bias. The final quantity of the bias will not be uniform for all of the countries as it will depend on the structures of the population by age and the levels of victimization incidence by age.

\section{(Figure 1 about here)}

Contrary to age, the gender variable is distributed in the sample and in the target population in a very similar way, with the largest difference in the case of Spain and Ireland —always being lower than $1 \%$, overestimating in favour of the male sex-. However, when the age and sex variables are broken down into five-year intervals, it can be observed that men have a greater weight in the $25-39$ year-old segment (as mentioned above, the age range that is frequently underestimated), while women 
tend to be predominant in the older age groups, between 50 and 70 years old (the overestimated group). In this situation, if we assume that the probability of being a victim of a crime is higher among men, given that they are concentrated in the underestimated age range, the victimization rate obtained would be lower than the real rate.

Differences in the structure in terms of household size. The distribution of the registers of the ICVS sample according to household size does not match the structure provided by the official EU-SILC. In Figure 2, the differences between the population percentages that the ICVS sample assigns to each household size (one, two, three, four, five, six or more members) and those derived from the EU-SILC are represented. The ICVS underestimates the single-person households and, although to a lesser extent, those formed by two people. In average, the weight of the former is reduced by about 12-15 percentage points -although in the case of the United Kingdom by 20 points - and the weight of the latter is reduced by around seven percentage points. On the contrary, the ICVS overestimates by between five and ten percentage points the households of four members —in Spain, by to up to 15 points—; the five-member households are overestimated by around five percentage points and finally, households with six members or more are overestimated by one or two points. 
It may be assumed that individual characteristics such as age or gender can determine a higher or lower risk of victimization but there is no reason to assume that the probability will vary depending on the size of the household to which the individual belongs. Therefore, these differences in the distribution of the sample and the population do not necessarily cause biases in the ICVS aggregate victimization rates. However, we shall see later that when these deviations in the sample structure are crossed with the way in which the victimization questions are asked to the respondents, a significant overestimation of victimization may occur.

\section{(Figure 2 about here)}

Differences in the structure of the labour market. Figure 3 shows the differences between the labour market status (employed, unemployed and inactive) in the ICVS weighted sample and in the EU-LFS. It is unquestionable that the ICVS underestimates the population in the category of employed people — which it does by more than six percentage points in the case of Spain-. On the other hand, it has a strong tendency to overestimate the inactive group —which, again, in Spain amounts to up to eight points above the LFS-.

\section{(Figure 3 about here)}


It is possible that part of these differences can be explained by the fact that in the ICVS individuals self-classify themselves depending on their labour status, while in the LFS they are classified in accordance with the responses to a series of questions. However, this would not justify such large differences or the systematic deviation of the ICVS towards the inactive population. It would be more reasonable to think that in the same way that the survey better captured the older age ranges, between 50 and 70 years, it also finds the inactive group more easily as they are the people who are most likely to be at home when they are called on their landlines. If one of the three inactive groups — retired people, householders and students — displayed a higher victimization rate than the group of people in the labour force, the rates estimated by the ICVS would be overestimating the incidence of crime.

Victimization of the individual or of the household and the consequences of reweighting large-sized households

As previously indicated, the incidence rates estimated by the ICVS have been obtained by weighting the respondents in accordance with their individual weight in the target population. The alternative option, of weighting the responses of each participant in accordance with the weight assigned to their household with respect to the total households in the country, has been discarded in the survey as the weighting factors of households were not provided by hardly any of the countries. ${ }^{14}$ This choice does not 
affect the victimization rates in any way provided that the questions of the ICVS regarding whether respondents have been victims to crime are limited to the facts occurring strictly to the individual and not to all of the members of the household. If elevation factors of the surveyed household (through one of its members) were used, the victimization questions should, logically be applicable to all of the household's members.

In the ICVS-2004/05 questionnaire, questions in which the victim can be both the individual and the members of the household can be found. Specifically, victimization referring to theft of/from cars, of motorcycles and bicycles and car vandalism is investigated and counted independently of the member of the household who suffered the act. All other crimes are counted only if the person being interviewed was victim to them. ${ }^{15}$ In this way, the victimizations declared by an individual include crimes suffered by all of the members of the household and when this victimization incidence is multiplied by the individual weighting factors, the result is an overestimation of the aggregated rate. ${ }^{16}$

Table 2 shows an assessment of what this overestimation could represent. In order to simplify, it is assumed that the target population is formed by seven people distributed among two households. The first household, to which individual 1 belongs, 
is made up of six members. The second is a single-person household and its only member is individual 2. Individual 1 and individual 2 are the only interviewees.

Focusing on the top part of the table (Section A), individual 1 has experienced two victimizations. However, the six members of the household of individual 1 —including him/her — have suffered up to seven criminal offences over the year prior to the survey. For individual 1 , the victimization rate on an individual level is $200 \%$ ( 200 crimes for every 100 people). However, taking into account the seven crimes committed against all of the members of the household -as is the procedure of the ICVS - and the individual elevation factor that is used, the victimization rate almost quadruples, reaching $700 \%$. Individual 2, who belongs to the single-person household has a victimization rate of $200 \%$ in all cases. The representative aggregate rate is the ratio between the number of victimizations declared and the interviewed population. Table 2 (Section A) shows that its value for household victimization (450\%) is more than double that of individual victimization (200\%).

In consequence, comparing victimization rates between countries those with more sized households will have, ceteris paribus, a (false) higher victimization rate. Or, comparing the same country over time, a simple change in the structures of households would generate variations in the national victimization rates. 
However, it does not end here. One of the requirements of the random sampling statistical technique is that all of the respondents must have the same probability of being selected for interview. As previously mentioned, the official report of the ICVS-2004/05 (Van Dijk et al., 2007: 191) indicates that due to the fact that the people who live in households with different number of members have different probabilities of being selected, ${ }^{17}$ a re-weighting procedure is required. As respondents from large households have a lower probability of being selected the adjustment consists in assigning them a higher weight ex-post. Otherwise, the interviewees belonging to small households would be over-represented.

This re-weighting is a standard procedure in a two-stage sampling (the random selection of a household and the random selection of a person in that same household). Without this correction, the sample design would not be consistent with the assumption of basic random sampling theory in which all of the individuals should have the same probability of being surveyed. However, in the ICVS, when the victimization is counted for all of the members of the household and not exclusively for the individual, the overestimation of criminality increases as the large households are given even more weight. Section B of Table 2 shows that when the weighting factor of individual 1 increases (as the household is made up of six members) from 1 to 1.75 , the 
victimization rate rises to $1,225 \%$. As the increase in the weight of individual 1 has been compensated by a reduction in that of individual 2 , the victimization rate of individual 2 is also affected, in this case by a decrease. Overall, when the re-weighting is conducted in accordance with household size, the total victimization rate of the population would increase from $450 \%$ to a very high figure of $638 \%$.

We cannot prove directly the existence of this second bias in the ICVS because the individual weighting factors before their correction in accordance with household size are not available. But we are going to try to illustrate its scope by showing that for the group of crimes for which victimization is recorded for all of the members of the household, an increase in the size of the household is significant because it implies an increase in the victimization rate. This should not occur if we contemplate the group of crimes for which victimization is recorded only on an individual level in the ICVS.

Unfortunately, this exercise cannot be carried out with the ICVS-2004/05, as in this wave only the variable referring to the total number of members of the household is available and not exclusively those members aged 16 years or more. It would not be appropriate to make the calculation with all of the members of the household, because criminal acts are only counted for the population aged 16 and over, so the rate would lose sensitivity to the household size: the numerator of the victimization ratio (number of criminal offences) could remain constant while the denominator 
(people in the household) could increase when children are added, thereby calculating a (false) decrease in the incidence with the increase of the number of members of the household. Therefore, the alternative option of resorting to the use of other previous waves of the survey that include this information has been chosen. In particular, the 1989 survey available for France, Germany, Spain and the United Kingdom, the 1992 one for Italy and the survey conducted in 2000 for Portugal have been used.

The victimization rates estimated for these six countries ${ }^{18}$ show the sensitivity of the group of household victimization crimes to the size of the household (Figure 4), whereby the average rate rises as the number of household members increases (left part, Figure 4). In contrast, this regularity is not found with individual victimization crimes (right part of the figure). In this case, the rates are much more irregular in relation to household size. As there have been no methodological changes in the ICVS, we can assume that this effect observed in 1989, 1992 and 2000 is the same in 2005, so the existence of this second bias is therefore (indirectly) demonstrated.

(Figure 4 about here)

\section{A (partial) estimate of the biases in the criminalization rate of the ICVS- 2005}

Although it would be more appropriate to estimate the biases generated by both i) the mismatches between the final structure of the sample and the target population and 
ii) the household victimization combined with the re-weighting of individuals depending on the size of the household, in this section only the former is quantified. As mentioned above, the unavailability of the variable referring to the size of the household in accordance with the members aged 16 or over in the ICVS 2005 prevents us from calculate the second bias. ${ }^{19}$

In order to assess the distortion generated by the differences between the weighted sample and the target population we have followed a very simple method. The aggregate victimization incidence rate $(V R)$ is the sum of the victimization rates of the different population categories " $i$ " $\left(V R_{i}\right)$ weighted by the participation of the corresponding category in the total $\left(W_{i}\right)$. In general, for " $n$ " categories of a variable the aggregate victimization rate will be:

$$
V R=V R_{1} * W_{1}+V R_{2} * W_{2}+\cdots+V R_{n} * W_{n}, \text { where } \sum_{i=1}^{n} W_{i}=100
$$

Obviously, if the victimization rates broken down by categories are not constant and the weights of the categories in the total are modified, the resulting $V R$ in equation (1) will be different.

In our case, we have used the weighted sample of the ICVS-2005 to estimate the victimization incidence rates by categories for the variables of sex, age, household size and labour force status. These victimization rates have been applied to the 
distribution of categories of each variable depending on the survey and the external source. And finally we have compared the aggregated rates of the ICVS-2005 with those obtained from the EUROSTAT information.

$\underline{\text { Figures } 5}, \underline{6}, \underline{7}$ and $\underline{8}$ show that in all of these variables the victimization rates broken down by categories vary significantly. Specifically, Figure 5 shows that there are differences in victimization between men and women. While in Portugal (or France) the incidence rate among men is more than six (five) points above that of women, in Germany male victimization is lower and almost eight points below that of women. In $\underline{\text { Figure } 6}$ it can be observed that the victimization rates do not remain constant and are related to the age of the population. Therefore, for all of the countries considered, the ICVS-2005 estimates a clearly decreasing trend in victimization as the age of the respondents increases.

(Figures 5 and $\underline{6}$ about here)

Furthermore, the victimization rates vary in accordance with the categories of the other two variables examined. First, and significantly, as the size of the household increases, the victimization of the individuals interviewed also increases (see Figure 7). On the other hand, although to a much lesser degree, Figure 8 shows that victimization incidence is slightly lower for the inactive population than for people in work or 
unemployed, and that the value of the rate is extremely high for unemployed people in Spain and the United Kingdom.

\section{(Figures 7 and $\underline{8}$ about here)}

After the rates were calculated by category, they were applied to both the structure of the weighted sample of the ICVS-2005 and the target population structure available in the EUROSTAT. In this way, the value of the $V R$ of equation (1) has been estimated for each of the two distributions. Finally, the difference between the aggregate victimization rate initially estimated by the ICVS-2005 and the alternative rate estimated with the distributions by gender, age, household size and labour force status of the EUROSTAT population has been calculated. This is shown in Table 3 and can be interpreted as the quantity of the bias.

\section{(Table 3 about here)}

The first column of the table presents the ICVS-2005 aggregate victimization incidence rates for the seven countries selected. In order to make our results comparable with those of the survey report (Van Dijk et al., 2007), only nine crimes are taken into account, namely: theft of/from a car, theft of a motorcycle, burglary, attempted burglary, robbery, theft of personal property, sexual offences and assaults \& threats. The only difference between the rates of the report and our rates is that 
those of the ICVS-2005 report distinguish between sexual offences against women and those against men (Van Dijk et al., 2007: 249-252), whereas in Table 3, in order to simplify, the victimization rate for this crime has been calculated jointly for both sexes.

The four remaining columns of Table 3 show, for each of the variables analysed, the difference between the victimization rate calculated according to the population structure provided by the EUROSTAT and that of the ICVS-2005. These differences would therefore be what the victimization rate of the ICVS should increase (if they have a positive sign) or decrease (if they have a negative sign) by in order to adjust to the supposedly non-biased victimization rates. In other words, the differences measure the upward biases (overestimations) or downward biases (underestimations) of the ICVS-2005.

The biases shown in the table cannot be aggregated because part of the effect of the deviations in one variable is included in the rest and if they were added together the impacts would overlap. Neither can the results of crossing the categories of the different variables be presented as their statistical significance cannot be guaranteed. Taking this into account, $\underline{\text { Table } 3}$ reveals that the biases in the victimization rate of the ICVS are by no means uniform. It also shows that the same variable has a different effect depending on the country and finally, it shows that the biases associated to the household size variable are, by far, much larger than the rest (for example, by more 
than five and seven points for the United Kingdom and Ireland respectively). Finally, the biases generated by the deviations in the age and labour force status variables are not as high as those associated to the household size but they are substantial for some countries, such as Ireland or Spain.

\section{Conclusions}

Although times of crisis have a negative effect on furthering and deepening European integration, the medium and long-term EU project should always be borne in mind. The need for a harmonized victimization survey derives from the importance of obtaining statistically reliable information regarding the incidence of delinquency in the countries of the EU. This has a double application: to establish criminal policy decisions on a European scale, ${ }^{20}$ and to provide the member states with better information so that they can adopt their own criminal policies.

Therefore, we agree with Van Dijk (2015) when he calls for the need for a European victimization survey such as the flawed EU Safety Survey (EU-SASU). In this sense, the principal contribution of this study is to demonstrate that the formulation of certain questions in which the victim can be any member of the household, when the responses of the interviewee are also re-weighted if he or she belongs to a large household, can cause a significant bias in the national victimization rates. This can lead 
to an erroneous ranking of the countries in accordance with the degree of incidence of victimization. This is a highly relevant result because the questionnaire proposed by the experts of the task force for the EU-SASU (Van Dijk et al., 2010: 59-61) still contains the questions in relation to certain crimes committed against any of the members of the household.

Furthermore, throughout the study we have revealed other results which should be taken into account in the design of either a future EU-SASU or the next waves of the ICVS. It is suspected that the way in which the survey is conducted (usually by phone), has apparently biased the sample towards those groups who are most likely to be found in the household where the landline which has been called is located. With the available information, it is not possible to estimate the joint effect of all the overestimated categories of the variables analysed ( 50 to 70 year-olds, women and inactive). But if this group is more (or less) victimized than the rest, this would determine a greater (or lesser) incidence rate. 


\section{Notes}

${ }^{1}$ Blumstein and Petersilia (2000: 199).

${ }^{2}$ Aebi and Linde (2011) or Lewis (2012).

${ }^{3}$ An example can be found in the recent study conducted by Campistol and Aebi (2017) referring to the comparability of juvenile criminal justice statistics across 45 European countries.

${ }^{4}$ Political and criminal factors referred to by Aebi (2010: 212). Systematizing them, Pérez-Cepeda (2016: 66-67).

${ }^{5}$ See European Parliament (2012a, b). For victimization surveys on a national level created in European countries see Zauberman (2008), Aebi and Linde (2010), Van Dijk et al. (2010, Annex D) and also Robert (2009). In particular, in the latter study, the police figures are compared with those drawn from the surveys for six European countries.

${ }^{6}$ See Van Dijk (2015). A retrospective view of the main findings based on the ICVS can be found in Van Kesteren et al. (2014).

7 The ICVS website (http://wp.unil.ch/icvs/, hosted by the University of Lausanne, Switzerland) includes the database, the methodology and the survey reports.

${ }^{8}$ Van Dijk et al. (2007: 191).

${ }^{9}$ For example, it could well be that the administration of the survey by phone biases the results towards the victimization of people who usually stay at home and it seems logical to think that those who have not experienced any victimization episodes will be much less interested in responding to a phone survey.

${ }^{10}$ In fact, the ICVS microdata file covers the period 1989-2005. This was obtained from the Easy Online Archiving System (see https://easy.dans.knaw.nl/ui/datasets/id/easydataset:44578/tab/2) and that for the codes of the variables can be found in: http://wp.unil.ch/icvs/codebooks/.

${ }^{11}$ Van Kesteren (2007: 9-17) and Van Dijk et al. (2007: 40).

12 The reasoning is similar to that used by Toharia (1998) or Pérez-Infante (2006) to explain how the Spanish Labour Force Survey underestimated the volume of employment a few years ago. In that case, the ageing of the sample in relation to the 
target population and the difficulties encountered in the fieldwork to find employed people (and also households in which all of the active residents were employed) meant that they were ultimately replaced with other units. Consequently, the final structure of the sample did not correspond to that of the target population, leading to an erroneous underestimation of employment.

${ }^{13}$ INE (on-line) and EUROSTAT (on-line a).

${ }^{14}$ See Van Kesteren (2007: 9-17) and Van Dijk et al. (2007: 40).

${ }^{15}$ See the questionnaire in Appendix 8 of the survey report in Van Dijk et al. (2007). Specifically, in question Q-32, the interviewer clarifies for the respondent that questions will be asked about the crimes experienced by the individual or his or her family, while in question Q-66 the interviewer asks about the crimes suffered exclusively by the interviewee.

16 The same method was used in the Encuesta a Víctimas en España (Spanish Victimization Survey) in 2008, conducted by the Observatorio de la delincuencia en Andalucía in which the same ICVS questionnaire was used (see Díez-Ripollés and García-España, 2009 or García-España et al., 2010). This was not the case for the Enquesta de seguretat pública de Catalunya, carried out by the Generalitat de Catalunya since 1999, which includes questions about episodes of victimization exclusively suffered by the interviewee (see Generalitat de Catalunya, 2016).

${ }^{17}$ For example, in a home with five members aged 16 or over - the age range of the interviewees - the probability that one of them is interviewed is one in five, while if the household were made up of just two people, the individual probability would be much higher, at one in two.

${ }^{18}$ Ireland cannot be included because no other surveys apart from the 2005 wave have been carried out.

${ }^{19}$ The strategy followed in the previous section using the information from the ICVS of other years has demonstrated that the bias exists, but it cannot be used to estimate the quantity of this distortion in the year 2005, as it would not be reasonable to transfer the victimization rate structures of 1989, 1992 or 2000 to the ICVS of 2005.

20 Despite the debated direct competence of the EU to create criminal law, not recognized in any of the regulatory instruments of the Union, it is evident that it has the capacity and applies it in order to harmonize the criminal provisions of the member countries, imposing direct obligations on the states to punish certain conducts. In any case, regarding the point during the UE process when crime data should be used by policymakers, see Pérez-Cepeda et al. (2013: 130-137). 


\section{References}

Aebi MF (2010) Methodological Issues in International Comparisons of Recorded Crime: The Role of Statistical Counting Rules. In: Shoham SG, Knepper P and Kett $\mathrm{M}$ (eds.) International Handbook of Criminology. CRC Press, pp. 211-228.

Aebi MF, Killias M and Tavares C (2002) Comparing Crime Rates: The International Crime (Victim) Survey, the European Sourcebook of Crime and Criminal Justice Statistics, and Interpol Statistics. International Journal of Comparative Criminology 2 (1): 22-37.

Aebi MF and Linde A (2010) Las encuestas de victimización en Europa: evolución histórica y situación actual. Revista de Derecho Penal y Criminología 3: 211-298.

Aebi MF and Linde A (2011) Conviction Statistics as an Indicator of Crime Trends in Europe from 1990 to 2006. European Journal on Criminal Policy and Research 18(1): 1-42.

Blumstein A and Petersilia J (2000) Investing in Criminal Justice Research. In: Cooper SH (ed.) Criminology. Coursewise, pp. 189-201.

Bouten E, Goudriaan H and Nieuwbeerta P (2003) Victimación delictiva en 17 países industrializados. Revista Española de Criminología 1: 1-21.

Campistol C and Aebi MF (2017) Are juvenile criminal justice statistics comparable across countries? A study of the data available in 45 European nations. European Journal on Criminal Policy and Research (first oline 17 June 2017): 1-24.

Delmas-Marty M (1990) A favor de unos principios orientadores de legislación penal. Anuario de Derecho Penal y Ciencias Penales 3: 961-966.

Díez-Ripollés JL and García-España E (dirs.) (2009) Encuesta a Víctimas en España, Observatorio de la delincuencia en Andalucía. Instituto Andaluz Interuniversitario de Criminología (Sección de Málaga) and Fundación Cajasol, Málaga (Spain).

European Commission (2011) Proposal for a Regulation of the European Parliament and the Council on the European statistics on safety from crime (COM (2011) 335 final).

European Commission (2012) Communication from the Commission to the European Parliament and the Council, Measuring Crime in the EU: Statistics Action Plan 2011- 2015 (COM(2011) 713 final), Brussels (Belgium).

European Parliament (2012a) European Parliament legislative resolution of 12 December 2012 on the proposal for a regulation of the European Parliament and of the Council on European statistics on safety from crime (COM(2011)0335 - C70155/2011 - 2011/0146(COD)). 
European Parliament (2012b) Report on the proposal for a regulation of the European Parliament and of the Council on European statistics on safety from crime (COM(2011)0335 - C7-0155/2011 - 2011/0146(COD)). Committee on Civil Liberties, Justice and Home Affairs (A7-0365/2012).

EUROSTAT (2015) EU Trends in statistics on police-recorded crime and the criminal justice system, 2008-2013. Statistics in Focus 3.

EUROSTAT (2016a) Crime and Criminal Justice Statistics - Methodological guide for users, 2016 Version (updated 25 May 2016).

EUROSTAT (2016b) Crime and Criminal Justice Statistics - Reference metadata at Country Level, 2016 Version (updated 17 May 2016).

EUROSTAT (2016c) Crime and Criminal Justice Statistics - Crime and Criminal Justice Statistics - Summary Quality Report on the 2015 Data Collection (may 2016).

EUROSTAT (on-line a) Statistics on income, social inclusion and living conditions (http://ec.europa.eu/eurostat/web/ income-and-living-conditions/overview))

EUROSTAT (on-line b) Main features of the EU-LFS and scope of data (http://ec.europa.eu/eurostat/web/lfs /overview).

García-España E, Díez-Ripollés JL, Pérez-Jiménez F, Benítez-Jiménez MJ, and CerezoDomínguez Al (2010) Evolución de la delincuencia en España: Análisis longitudinal con encuestas de victimización. Revista Española de Investigación Criminológica 8.

Generalitat de Catalunya (2016) Enquesta de seguretat pública de Catalunya, Edició 2015

(http://interior.gencat.cat/ca/el_departament/publicacions/seguretat/estudis_i_ enquestes/enquesta_de_seguretat_publica_de_catalunya/enquesta_de_egureta t_publica_de_catalunya_2015/).

Heinz A (2016) Methodological Lessons learned from the Luxembourgish Safety Survey. In: 16th Annual Conference of the European Society of Criminology (Eurocrim 2016), Münster (Germany).

INE (on-line) Living Conditions Survey (http://www.ine.es/dyngs/INEbase/en /operacion.htm?c=Estadistica_C\&cid=

1254736176807\&menu=ultiDatos\&idp $=1254735976608$ )

Lewis C (2012) Crime and Justice Statistics Collected by International Agencies. European Journal on Criminal Policy \& Research 18(1): 5-21.

Mankkinen T (2008) Value of Victimisation Surveys for Decision Makers. In: KaukoAromaa $\mathrm{K}$ and Heiskanen $\mathrm{M}$ (eds.) Victimisation Surveys in Comparative Perspective. European Institute for Crime Prevention and Control, affiliated with the United Nations (HEUNI), Papers from the Stockholm Criminology Symposium 2007, Helsinki (Finland), Publication Series 56: 132-135. 
Pérez-Cepeda Al (2016) Estadísticas sobre criminalidad en la Unión Europea. In: Becerra-Muñoz J, Nieto-Martín A and Muñoz de Morales-Romero M (dirs.) Hacia una evaluación racional de las leyes penales. Marcial Pons, pp. 49-77.

Pérez-Cepeda Al and Benito-Sánchez D (2013) Estudio de los instrumentos existentes para medir la delincuencia. Revista electrónica de Ciencia Penal y Criminología 15(08).

Pérez-Cepeda, Al, Benito-Sánchez D and Gorjón-Barranco MC (2013) Study on the policy-relevance of existing crime data. EUCLR European Criminal Law Review $3(2): 125-151$

Pérez-Infante $\mathrm{Jl}$ (2006) Las estadísticas del mercado de trabajo en España. Colección Informes y Estudios. Empleo. Ministerio de Trabajo y Asuntos Sociales. Madrid (Spain).

Robert P (ed.) (2009) Comparing Crime Data in Europe. Oficial Crime Statistics and Survey Based Data. VUBPRESS.

Silva-Sánchez JM (2011) La expansión del Derecho penal. Aspectos de la política criminal en las sociedades postindustriales (3a. Ed.). Madrid: Edisofer.

Toharia L (dir.) (1998) El mercado de trabajo en España. Madrid: McGraw Hill.

Van Dijk J (2015) The case for survey-based comparative measures of crime. European Journal of Criminology, 12 (4).

Van Dijk J, Mayhew P, Van Kesteren J, Aebi M and Linde A (2010) Final report on the study on crime victimisation. INTERVICT/Tilburg University \& EUROSTAT.

Van Dijk J, Van Kesteren J and Smit P (2007) Criminal Victimisation in International Perspective. Key findings from the 2004-2005 ICVS and EU ICS, Ministry of Security and Justice (The Netherlands), UNICRI and UNODC (http://www.unicri.it/services/library_documentation/publications /icvs/publications/ICVS2004_05report.pdf).

Van Kesteren J (2007) Integrated Database from the International Crime Victim Surveys (ICVS) 1989-2005, Data and Codebook -Version ICVS2005_3 (October, 2008). INTERVICT, Tilburg University.

Van Kesteren J, Van Dijk J and Mayhew P (2014) The International Crime Victims Surveys. A retrospective. International Review of Victimology 20(1).

Zauberman R (ed.) (2008) Victimisation and Insecurity in Europe: A Review of Surveys and Their Use. Vub University Press. 
Table 1. Summary of registers and codes for the selected countries. ICVS-2005.

\begin{tabular}{|l|c|c|}
\hline Country & Country code & $\begin{array}{l}\text { Number of } \\
\text { respondents }\end{array}$ \\
\hline Germany & 230 & 2,025 \\
\hline France & 210 & 2,016 \\
\hline Italy & 280 & 2,023 \\
\hline Spain & 490 & 2,034 \\
\hline Portugal & 425 & 2,011 \\
\hline Ireland & 275 & 2,003 \\
\hline $\begin{array}{l}\text { United } \\
\text { Kingdom }\end{array}$ & 555 & 2,004 \\
\hline Source: ICVS microdata $1989-2005$ and own elaboration.
\end{tabular}


Figure 1. Distribution (\%) of the ICVS-2005 sample and of the target population in five- year age groups. Selected countries. Year 2005

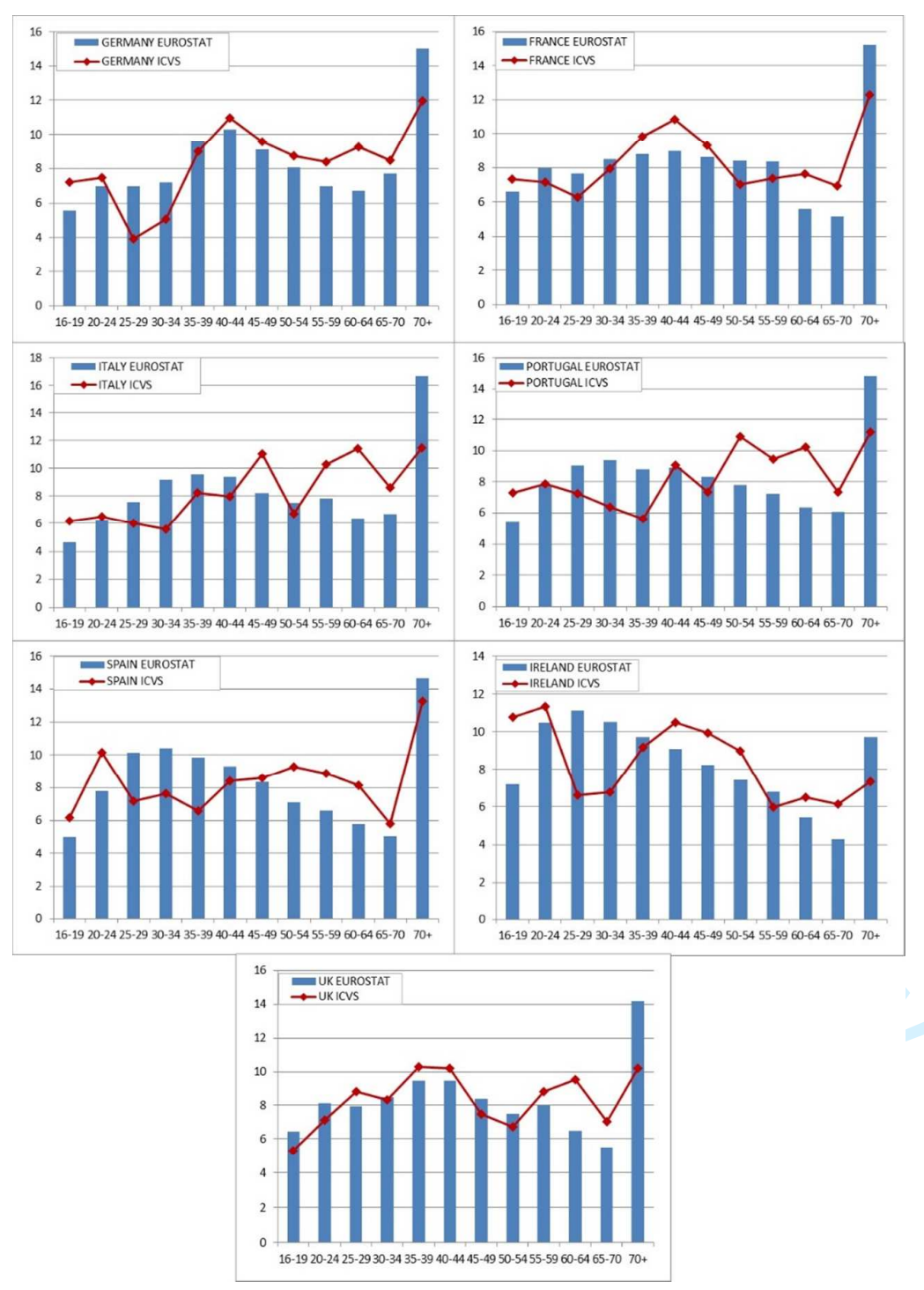

Source: ICVS microdata 1989-2005, EUROSTAT (Series: Population on 1 January by five-year age group and sex [demo_pjangroup]) and own elaboration. 
Figure 2. Differences in the distribution (\%) of the ICVS sample and the target population by size (number of people) of the household. Selected countries. Year 2005

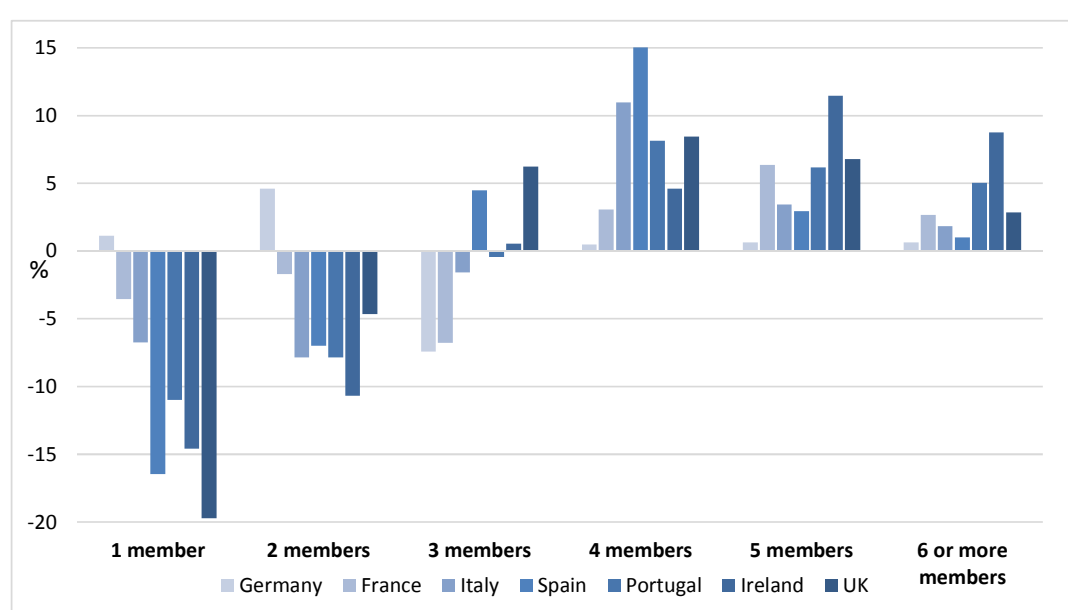

Source: ICVS microdata 1989-2005, EUROSTAT (Series: Distribution of households by household size EU-SILC survey [ilc_lvph03]) and own elaboration. 
Figure 3. Differences in the distribution (\%) of the ICVS sample and the target population according to the labour force status. Selected countries. Year 2005

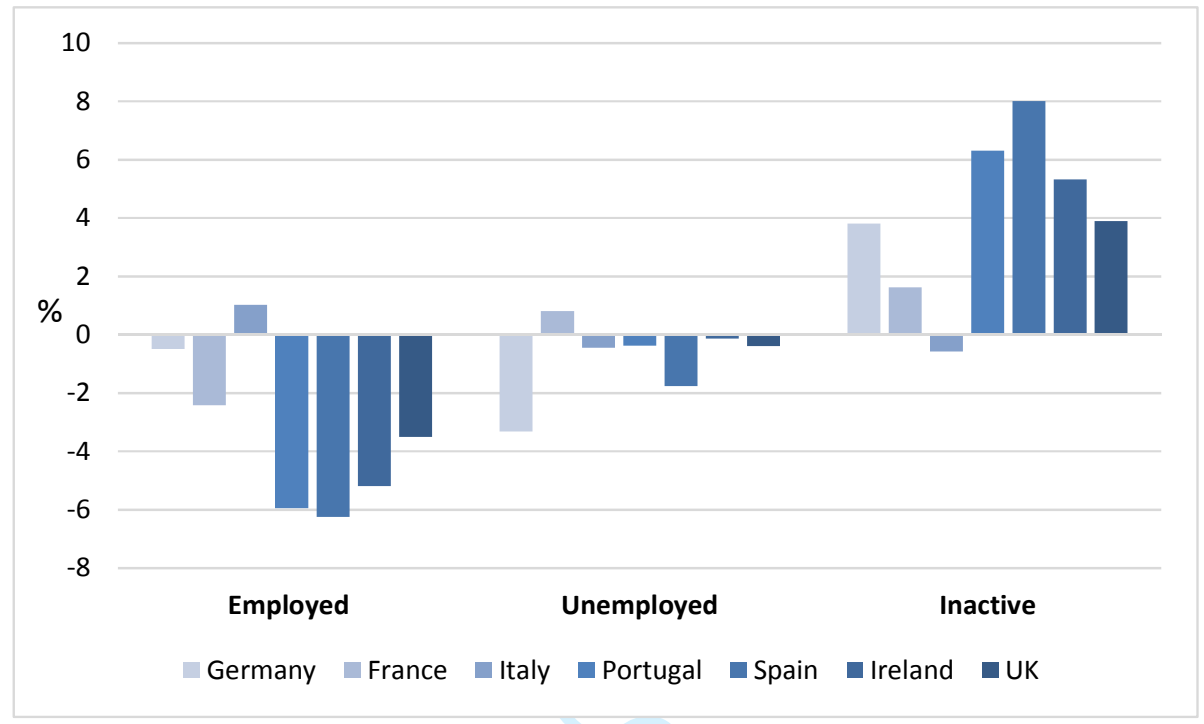

Source: ICVS microdata 1989-2005, EUROSTAT (Series: Population by gender, age, citizenship and labour status - EU-LFS [Ifsa_pganws] and own elaboration. 
Table 2. Changes in the incidence rate: an example

\begin{tabular}{|c|c|c|c|c|c|c|}
\hline & & $\begin{array}{l}\text { Number of } \\
\text { individuals } \\
\text { interviewed } \\
\text { (a) } \\
\end{array}$ & $\begin{array}{l}\text { Criminal acts } \\
\text { declared } \\
\text { (b) }\end{array}$ & $\begin{array}{l}\text { Individual } \\
\text { weighting } \\
\text { factor } \\
\text { (c) }\end{array}$ & $\begin{array}{l}\text { Number of } \\
\text { weighted } \\
\text { criminal } \\
\text { acts }\left(b^{*} c\right)\end{array}$ & $\begin{array}{l}\text { Victimization } \\
\text { rate }(\%) \\
(a * b / c) * 100\end{array}$ \\
\hline $\begin{array}{l}\text { SEC } \\
\text { IND }\end{array}$ & $\begin{array}{l}\text { TION A: INDIVIDUAL VIC } \\
\text { IVIDUALS INTERVIEWED }\end{array}$ & $\begin{array}{l}\text { MIZATION VS } \\
\text { ACCORDANC }\end{array}$ & $\begin{array}{l}\text { HOUSEHOLD I } \\
\text { WITH HOUSEF }\end{array}$ & $\begin{array}{l}\text { TIMIZATION } \\
\text { LD SIZE }\end{array}$ & VITHOUT RE & VEIGHTING THE \\
\hline-1 & Individual victimization & & 2 & & 2 & $200 \%$ \\
\hline 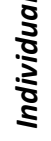 & $\begin{array}{l}\text { Household victimization } \\
\text { Individual } 1 \\
\text { ( } 6 \text { members) }\end{array}$ & 1 & 7 & 1 & 7 & $700 \%$ \\
\hline 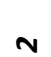 & Individual victimization & & 2 & & 2 & $200 \%$ \\
\hline 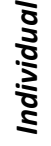 & $\begin{array}{l}\text { Household victimization } \\
\text { Individual } 2 \\
\text { (1 member) }\end{array}$ & 1 & 2 & 1 & 2 & $200 \%$ \\
\hline $\begin{array}{l}\text { TO } \\
\text { (inc }\end{array}$ & $\begin{array}{l}\text { TAL } \\
\text { lividual victimization) }\end{array}$ & 2 & (1) & & 4 & $200 \%$ \\
\hline $\begin{array}{l}\text { TOI } \\
\text { (ho }\end{array}$ & $\begin{array}{l}\Gamma A L \\
\text { usehold victimization) }\end{array}$ & 2 & & & 9 & $450 \%$ \\
\hline $\begin{array}{l}\text { SEC } \\
\text { IND }\end{array}$ & $\begin{array}{l}\text { TION B: INDIVIDUAL } \\
\text { IVIDUALS INTERVIEWED }\end{array}$ & $\begin{array}{l}\text { ICTIMIZATIOI } \\
\text { ACCORDANC }\end{array}$ & $\begin{array}{l}\text { VS. HOUSEI } \\
\text { WITH HOUSEF }\end{array}$ & $\begin{array}{l}\text { LD VICTIM } \\
\text { LD SIZE }\end{array}$ & ATION RE- & EIGHTING THE \\
\hline 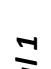 & Individual victimization & & 2 & & 3.5 & $350 \%$ \\
\hline : & $\begin{array}{l}\text { Household victimization } \\
\text { Individual } 1 \\
\text { ( } 6 \text { members) }\end{array}$ & 1 & 7 & & 12.25 & $1,225 \%$ \\
\hline$\stackrel{N}{N}$ & Individual victimization & & 2 & & 0.5 & $50 \%$ \\
\hline : & $\begin{array}{l}\text { Household victimization } \\
\text { Individual } 2 \\
\text { (1 member) }\end{array}$ & 1 & 2 & 0.25 & 0.5 & $50 \%$ \\
\hline $\begin{array}{l}\text { TOT } \\
\text { (ho }\end{array}$ & $\begin{array}{l}\text { TAL } \\
\text { usehold victimization) }\end{array}$ & 2 & & & 12.75 & $638 \%$ \\
\hline
\end{tabular}


Figure 4. Incidence rates for groups of crimes depending on whether victimization is calculated on a household or individual level, by household size. ICVS-1989, 1992 and 2000.

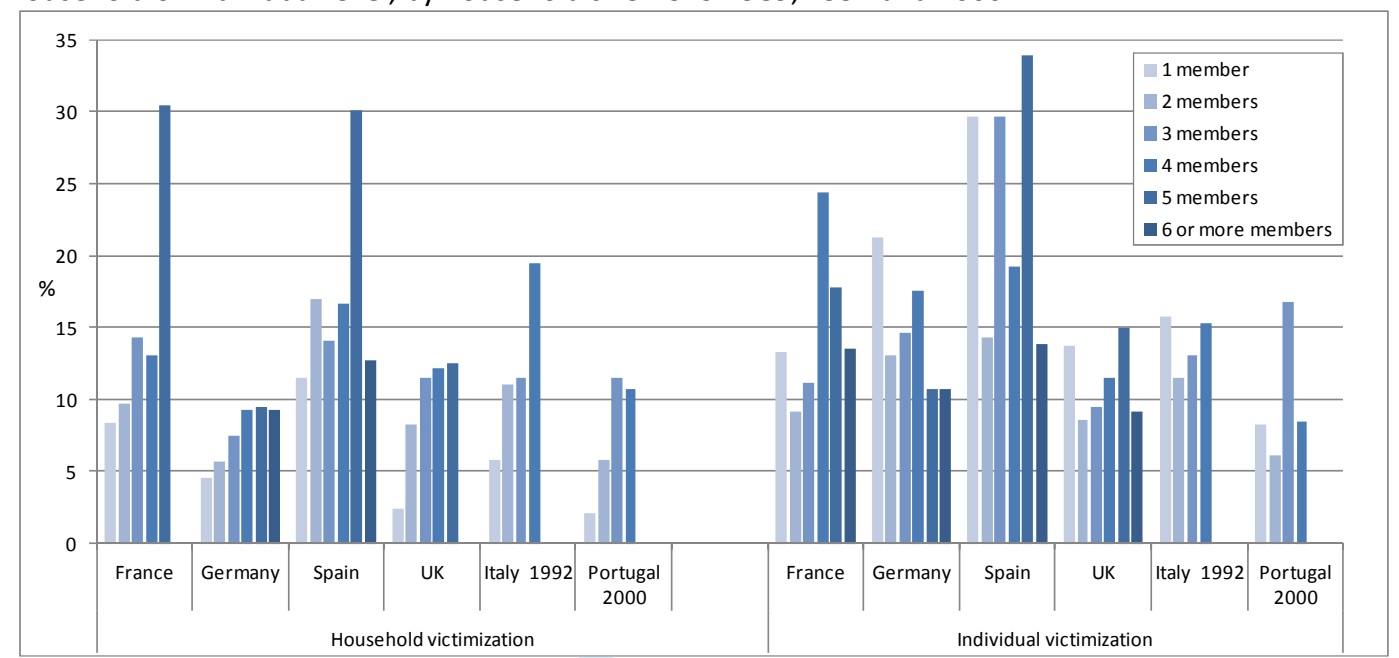

Source: ICVS microdata 1989-2005 and own elaboration. 
Figure 5. Incidence rates (\%) by sex. Weighted sample ICVS-2005.

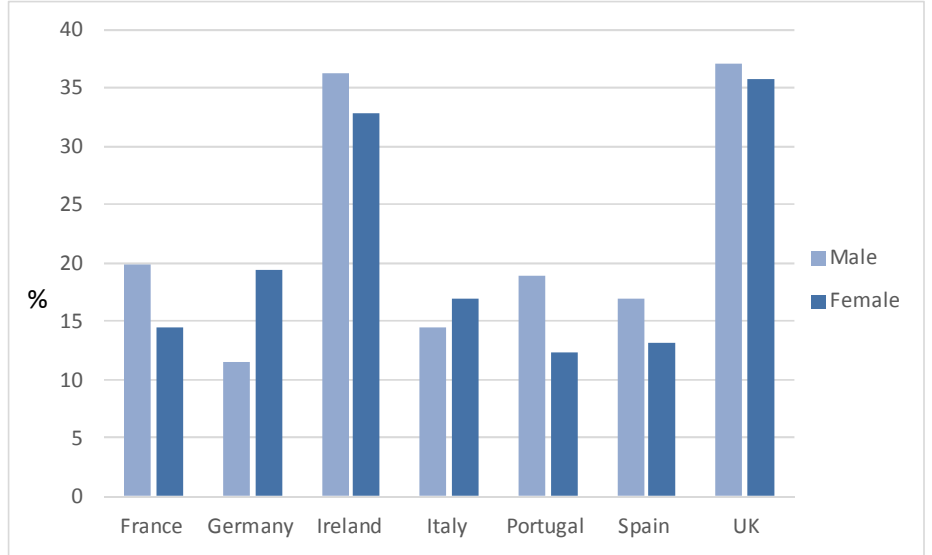

Source: ICVS microdata 1989-2005 and own elaboration. 
Figure 6. Incidence rates (\%) by large age groups. Weighted sample ICVS-2005.

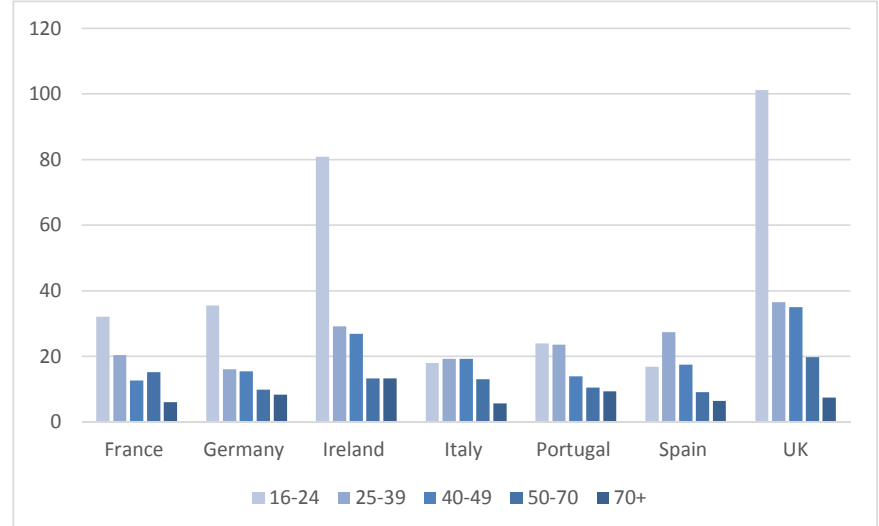

Source: ICVS microdata 1989-2005 and own elaboration. 
Figure 7. Incidence rates (\%) by household size. Weighted sample ICVS-2005.

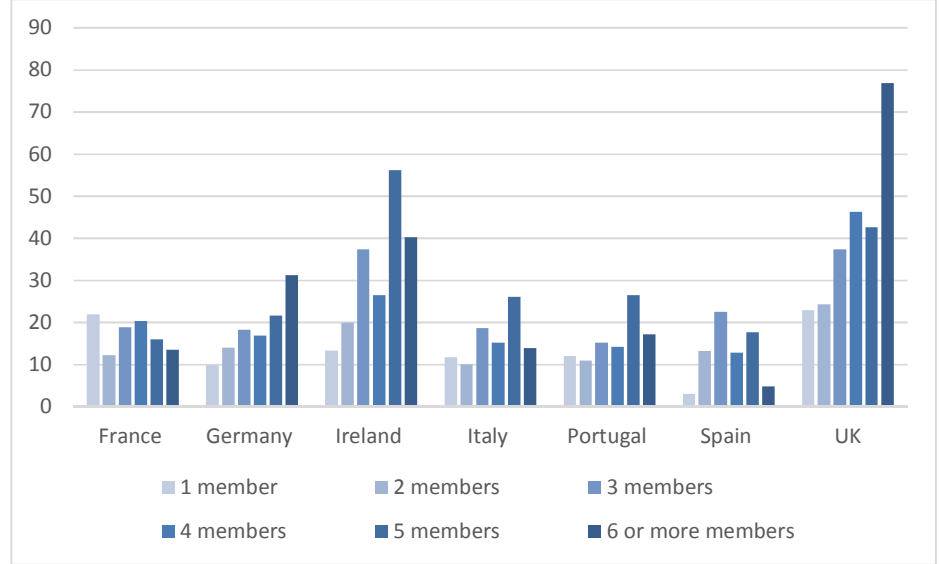

Source: ICVS microdata 1989-2005 and own elaboration. 
Figure 8. Incidence rates (\%) by labour force status. Weighted sample ICVS-2005.

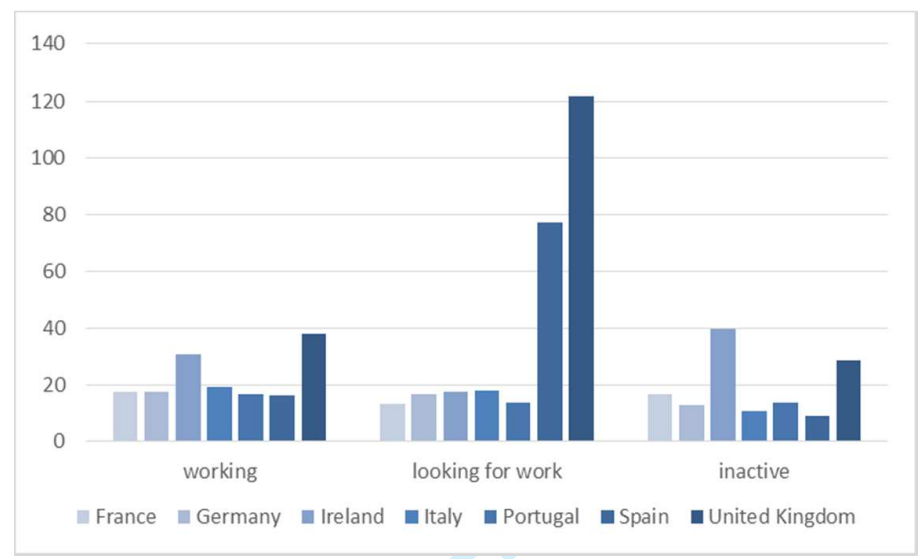

Source: ICVS microdata 1989-2005 and own elaboration. 
Table 3. Annual victimization incidence rate ICVS-2005 and estimates of the biases. Selected countries.

\begin{tabular}{|l|c|r|r|r|r|}
\hline Country & \multicolumn{4}{|c|}{$\begin{array}{c}\text { Victimization } \\
\text { rate* }\end{array}$} & \multicolumn{3}{|c|}{$\begin{array}{c}\text { Biases derived from the differences** in } \\
\text { the population structure by: }\end{array}$} \\
\cline { 3 - 6 } & $\begin{array}{c}\text { Gender } \\
\text { United Kingdom }\end{array}$ & Age & $\begin{array}{c}\text { Household } \\
\text { size }\end{array}$ & $\begin{array}{c}\text { Labour } \\
\text { force status }\end{array}$ \\
\hline Ireland & 36.35 & 0.00 & 0.97 & -5.69 & 0.70 \\
\hline France & 34.52 & 0.03 & -2.04 & -7.30 & -0.49 \\
\hline Italy & 17.11 & -0.02 & -0.13 & 0.26 & 0.05 \\
\hline Germany & 15.76 & 0.00 & -0.15 & -0.95 & -0.05 \\
\hline Portugal & 15.56 & -0.01 & -0.31 & 0.18 & 0.15 \\
\hline Spain & 15.51 & -0.01 & 0.79 & -1.42 & 0.18 \\
\hline
\end{tabular}

* Number of incidents during 2004 referring to the nine crimes selected in the ICVS-2005 for every 100 inhabitants.

** Difference in percentage points between the rates derived from the EUROSTAT target population and the ICVS-2005 weighted sample.

Source: ICVS microdata 1989-2005 and own elaboration. 